PORTIONS OF THIS REPORT : TLLEGLE. 11

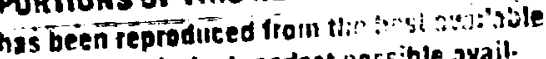
copy to permit the broadest anrsible ayail.

rilitis.
UCRL-90495

PREPRINT

C(NF - 8408.7 $7-3$

\title{
Gamma-Ray to Cerenkov-Light Conversion Efficiency for Pure-Silica-Core Optical Fibers
}

\author{
B. L. Pruett, R. T. Peterson, D. E. Smith,
} L. D. Looney, R. N. Shelton, Jr.

This paper was prepared for the Proceedings of the Society of Photo-Optical Instrumentation Engineers August 19-24, 1984

San Diego, CA

July 1984

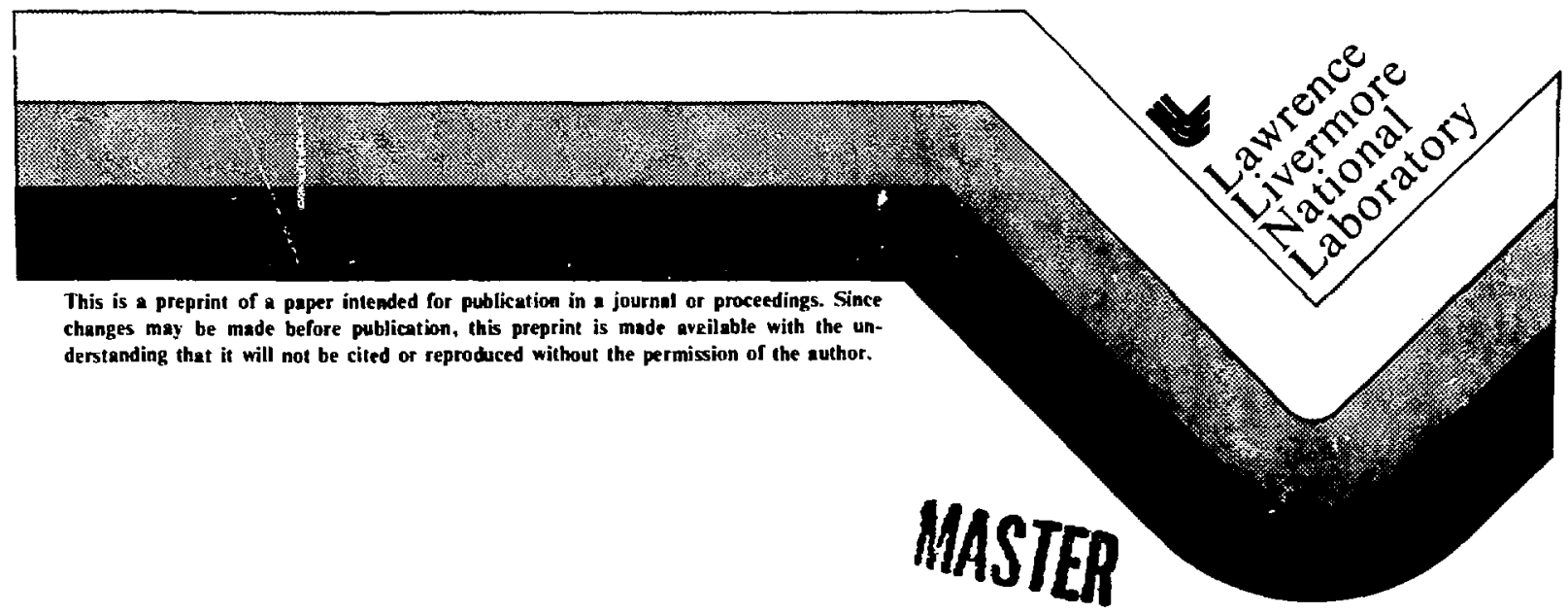




\section{DISCLAIMER}

This report wits prepared as an account of work sponsored by an agency of the United States Governmen. Neither the United States Goyernment nor any agency thereof, nor any of their employees, makes any warranly, express or implied, or assumes any legal liability or responsibility for the accusacy, completeness, of use[ulness of any information, apparatus, product, or process disclosed, or represents that its use would not infringe privately owned rights. Reference herein to iny specific commercial product, process, or service by trade name, trademark, manufacturer, or otherwise does not necessarily constitute or imply its endorsement, recommendation, or fayoring by the United States Government or any agency thereol. The views and opinions of authors expressed herein to not necessarily state or reflect those of the United States Government or any agency thereof. 


\title{
Gamma-Ray to Cerenkov-Light Conversion Efficiency tor Pure-Siliea-Core Optical Fibers
}

\author{
B. L. Pruett, R. T. Retersun, and D. E. Smith
}

Lawrence Livernure National Labaratory, University of Califurnis P.O. Box 808, Livermoie, California 94550

\section{D. Leaney and R. N. Shelton, Jr.}

Los Alamus National Laboratory, Los Alamos, New Mexicu 87545

\begin{abstract}
We have determined experimentally the absolute gamma-ray to Cerenkov-light conversion efficiency for pure-silica-core optical fibers in the vicinity of metallic Compton-converter slabs. To measure the energy dependence of this process, we used ${ }^{60} \mathrm{Co}$ and ${ }^{24} \mathrm{Na}$ radiation sources. The results show how the conversion efficiency varies with Compton-converter material, thickness, angle of the fiber, and fiber-converter distance. We alse performed computer calculations of conversion efficienc\%. This method employs an electrun-photon transport code named SANDYL together with analytical calculations of Cerenkov-light generation. We compare the results of these calculations with experimental results.

\section{Introduction}

Pure-silica-core optical fibers are used by the Lawrence Livermore National Laboratory (LLNL) and the Los Alamos National Laboratory (LANL) in high-bandwidth analog diagnostic sysi:ms for gamma rays, in the Nuclear Testing Program at the Nevada Test Site. An intense gamma-ray signal emitted from an exploding nucleas device is permitted to strike a "thin" slab of material, producing Cumpton electrons. The electrons pass through an optical fiber, which consequently generates a Cerenkov-light signal The light is then transmitted via a second Siber to a remote location for recording (Fig. 1). This diagnostic system is described in more detail by another paper in this session. ${ }^{1}$

Both LLNL and LANL have ongoing programs to optimize and characterize this optical-fiber diagrostic scheme. In these programs, ${ }^{60} \mathrm{Co}$ and ${ }^{24} \mathrm{Na}$ gamma-radiation sources are used in the laboratory to determine absolute gamma-ray to Cerenkov-light conversion efficiency and to investigate the effects of different fiber types and geometries. These characteristics are also investigated by computer calculations. The work described in this paper was done as part of the ongoing programs.
\end{abstract}

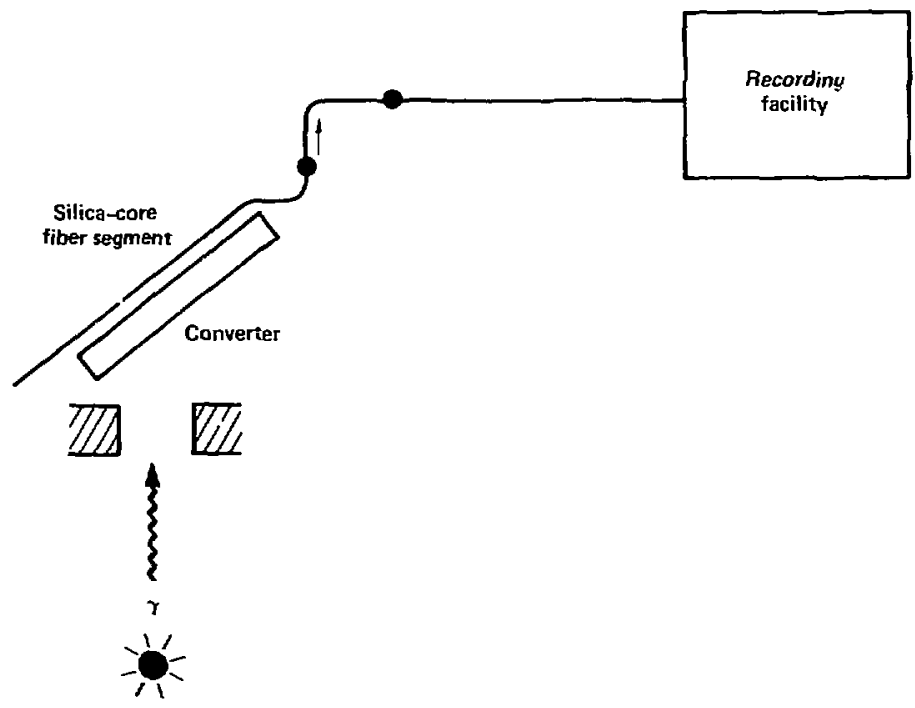

Figure 1. Diagram of a field diagnentic in whizh Cerenkow light is produced in an opgtical filter. 


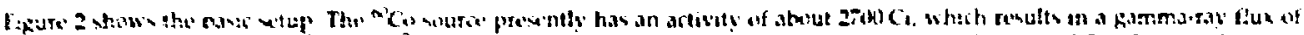

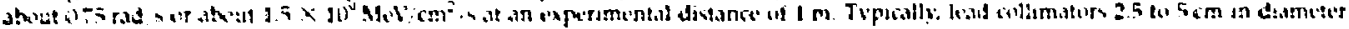

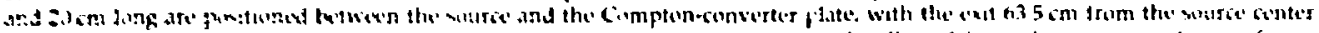

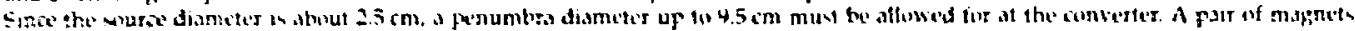

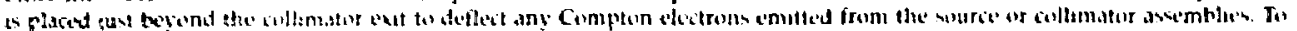

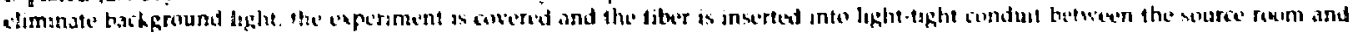
control rimen where the detedun syotem is lesided.

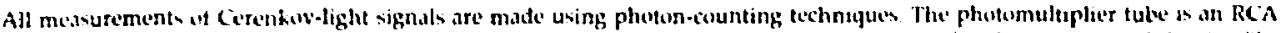

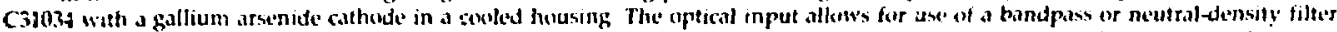
Counting sectronies consist of dn EG\&G Ortec (Oak Ridge. Tenn.) model 450 amplifier, an FGidG Ortec model 551 single-chinned analyzer, and a Canber ra (Miriden, Conn.) model 1776 counter. Typical signal count rates with this system range from abuut 10 to more than 7000 counts/s, while the photomultiplier bachgresund rate is about 1 count/s

\section{Absolute Conversion Efficiescy for ${ }^{\text {N) }}$ Cu Gamma Radiatuon}

A $\times$ Co gamma-ray source has siveral advantages in calibrating and characterizing Corenkov-light-producing fiber-optic diagnostics used in nuclear testing. The five-year ha!f-life minimizes the effort required to correct for intensity changes. The 1.17 - and 1.33-Mel' photon energies are similar to those measured for exploding nuclear devices. The continuous nature of the cobalt source permits the use of slow but sensitive optical detection systems. For pure-silica-care fibers, the gamma-ray flux level is insuificierit to cause fiber damage.

The absolute calibration scheme uses four me.ssurement steps, as shown in Fig. 3. The geometry for all the steps is the same except for the changes described below. At the input end of the fiber to be measured, a quartz-iodine light source is attached to a filter box. The box has a collimating lens; three slots for filters; a diffuser; and at the output end, a bulkhead feedthrough tor the fiber connection. The filter slots are angled at about $2^{\circ}$ to prevent light reflected off filter faces from reaching the diffuser. About $0.5 \mathrm{~m}$ beyond its input end, the fiber passes through the gamma-beam path, where it is attached to the Compton-converter plate. Within an additional $0.5 \mathrm{~m}$, the fiber is wrapped around a mode-stripping mandrel and then enters the protective conduit.

In step 1 of the measurement, light is transmitted through a bandpass filter placed in the filter box and strikes the diffuser, which is intended to fill ali transmission modes of the fiber. The optical power transmitted by the fiber is input io a calibrated United Detector Technology (San Diego, Calif.) PIN photodiode of sensitivity $S_{\mathrm{PD}}$, and its current output $i_{1}$ is measured with an electrometer. This step measures the absolute light power $P_{1}$ exiting the fiber at the wavelength interval determined by the filter:

$$
r_{1}=\stackrel{i_{1}}{S_{P D}}
$$

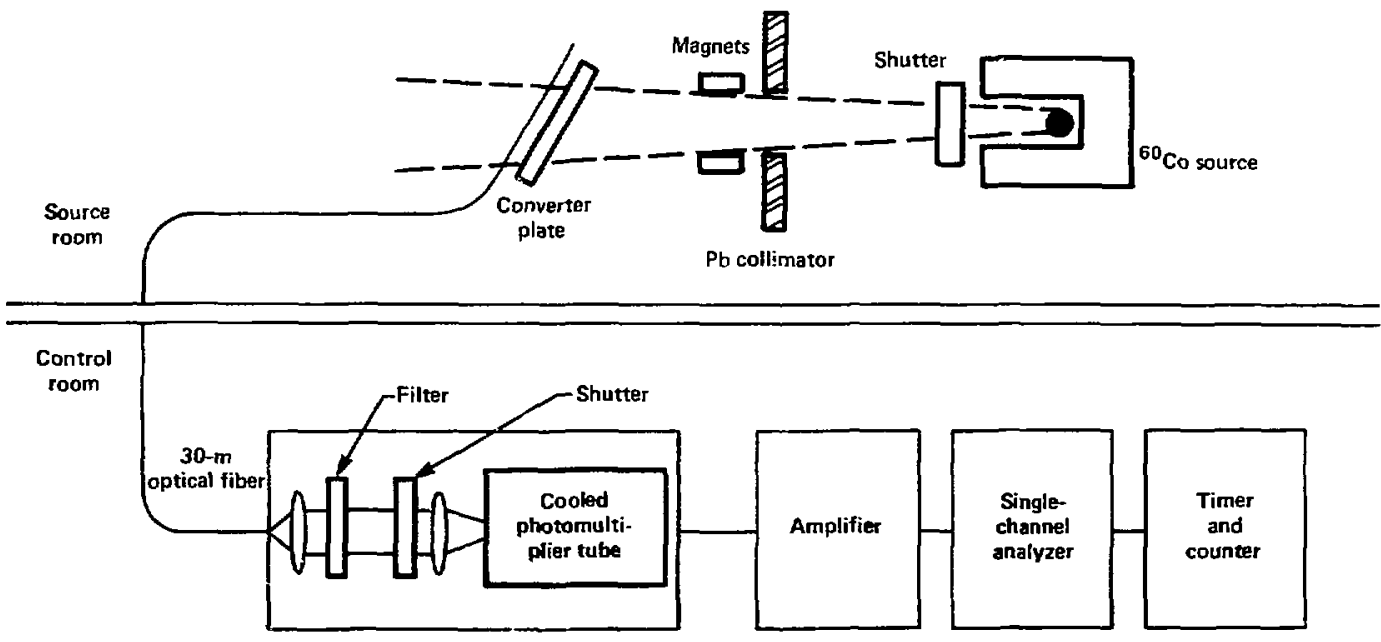

Figure 2 Diagram of the experimental sethp for measuring Cerenkov-light signals. 

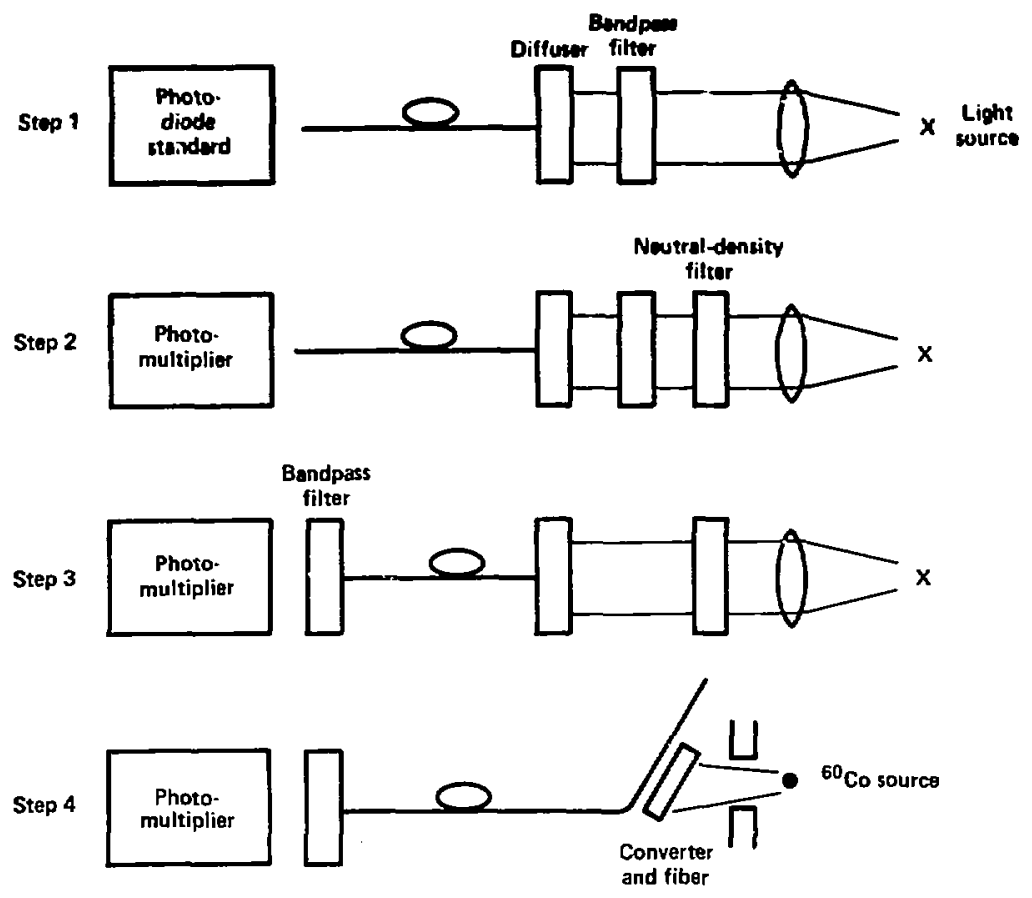

Figure 3. Sequence of steps in measuring the absolute conversion efficiency of gamma rays to Cerenkov light.

Step 2 is like step 1 except that the light is attenuated by neutral-density filters with transmission $T_{N D}$ placed in the filter box, and the fiber output $P_{2}$ is directed to the photomultiplier detector system. This generates the absolute sensitivity $S_{\mathrm{PM}}$ of the photomultiplier system at its optical input:

$$
S_{\Gamma M}=\frac{N_{2}}{P_{2}}
$$

where $N_{2}$ is the number of counts recorded for a prescribed time, and where

$$
P_{2}=T_{\mathrm{ND}} P_{1}
$$

Cerenkov light to be obtained in the fiber in step 4 below requires that the bandpass filter be moved to the photomuliiplier input. This change in geometry can cause small changes in light transinission through the system. Step 3 repeats the step 2 measurement atter the filter is repositioned at the photomultiplier, and the ratio of the two measurements, $N_{2} / N_{3}$. provides an appropriate correction factor

In step 4 the Cerenkov-light output power $P_{4}$ is measured when the converter and fiber are exposed to gamma radiation. The geometry is identical to that for step 3, with the light shutter closed and the cobalt-source shutter open:

$P_{1}=\begin{aligned} & N_{3} N_{2} \\ & S_{2 M} N_{3}\end{aligned}$

The absolute conversion efficiency $S_{c}$ for gamma-ray flux to Cerenkov-light output for the fiber can now be determined:

$$
S_{\mathrm{C}}=\frac{P_{\mathrm{A}} \eta_{\mathrm{Br}}}{\phi_{\mathrm{Con}} f_{\mathrm{F}}}
$$




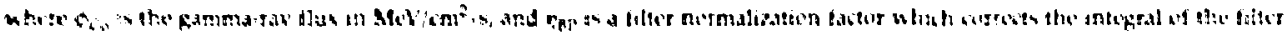

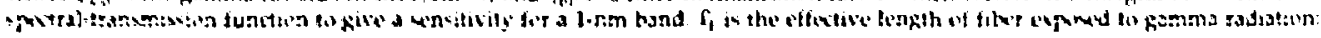

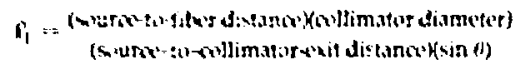

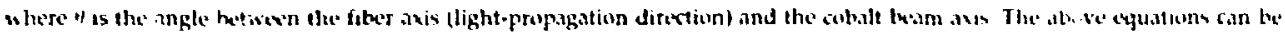
itmbinid porite:

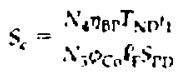

The results of stef $2, N_{2}$, cancel out in this equation The measurement is still maintaned in the 4 (4) factur dows rot vary greatly from a valus of 1.

Table I summarizes the measurements for three optical fibers and four wivelengths. The mumerical-aperture values given were measured with the step 3 fibu input geomeiry described above, and mode stripping was used. The strength of the light source did not permit bandpass filters to be used for these numerica'-aperture measurements.

The ${ }^{60}$ Co source suffers from internal Compton scattering, which causes significant low-energy gamma rays to be emitted. A uranium/graded- $Z$ filter ${ }^{2}$ was used to minimize this cuntribution. With the filter the average gamma-ray energy was about 1.1 MeV.

The uncertainty of the sensitivity data is estimated to be about $10 \%$. Most of the individual uncertainties were of the order of 37 .

\section{Effect of Compton-Converter Material on Efficiency}

Cerenkov light is emitted within an optical medium at an angle $\theta$ relative to an electron path. where cos $\theta=1 / \beta n ; \beta$ is the electron velocity and $n$ is the refractive index. This requires that $\beta$ be greater than $1 / n$. For $1-\mathrm{MeV}^{\prime}$ clectrons and $n \approx 1.46, \theta=43^{\circ}$

The angular distributions at which Compton electrons are emitted are given by the differential Klein-Nishina cross-section for electrons. ${ }^{3}$ This indicates that the Compton electron flux will be peaked in the gamma-ray beam direction and that these electrons will have the highest energies. To capture the maximum amount of Cerenkov light, the fiber should be placed at a $43^{\circ}$ angle with respect to the gamma-ray direction. For a Compton-converter plate of finite dimensions, however, the electrons will undergo scattering dependent upon the material type and thickness. Because low- $Z$ materials produce less scattering, they can be used to maximize the number of electrons that will produce Cerenkov light within the fiber acceptance angle. At the same time, fewer electrons at other angks will help minimize the fiber radiation damage relative to light production.

Table 2 shows mpasurements made with several materials. The measurements confirm that low- $Z$ materials pruduce the maximum amount of light. It should be noted that the fiber is also in the beam for all of these measurements. For the best measured material (beryllium), about $42 \%$ of the signal was derived directly from the fiber. This is due to Compton electrons produced in the fiber by gamma rays transmitted through the beryllium. For a jarger-diameter Raychem fiber the value is about $54 \%$.

\section{Fffect of Compton-Converter Thickness on Efficiency}

A series of measurements using beryllium converter plates of different thicknesses determines the signal vs thickness relationship. The angle between the converter/fiber and beam is maintained at $45^{\circ}$. Figure 4 shows the results for a plastic-clad silica

\begin{tabular}{|c|c|c|c|c|}
\hline & & \multicolumn{3}{|c|}{ Fiber type } \\
\hline & & $\begin{array}{l}\text { Raychem } \\
\text { VSC-200A }\end{array}$ & $\begin{array}{c}\text { IT\&T } \\
\text { PSO-5 (PCS) } \\
\text { Sample I }\end{array}$ & $\begin{array}{c}\text { IT\&T } \\
\text { PSO-5 (PCS) } \\
\text { Sample 2 }\end{array}$ \\
\hline $\begin{array}{c}\text { Physical characteristic } \\
\text { Core D diam }(\mu \mathrm{m}) \\
\text { Numerical aperture }\end{array}$ & & $\begin{array}{l}200 \\
\sim 0.28\end{array}$ & $\begin{array}{l}125 \\
\sim 0.39\end{array}$ & $\begin{array}{l}125 \\
\sim 0.39\end{array}$ \\
\hline $\begin{array}{l}\text { Conversion efficiency } \\
S_{\mathrm{c}}\left(\mathrm{J} / \mathrm{MeV} \cdot \mathrm{cm}^{2} \cdot \mathrm{nm}\right)^{\mathrm{a}} \text {. } \\
\text { at wavelength } \lambda\end{array}$ & $\begin{array}{l}\frac{\lambda(\mu \mathrm{m})}{570} \\
600 \\
700 \\
500\end{array}$ & $\begin{array}{l}16.8 \times 10^{-27} \\
10.9 \times 10^{-27} \\
7.28 \times 10^{-27} \\
5.22 \times 10^{-27}\end{array}$ & $\begin{array}{l}8.55 \times 10^{-27} \\
5.02 \times 10^{-27} \\
4.02 \times 10^{-27} \\
2.84 \times 10^{-27}\end{array}$ & $\begin{array}{l}- \\
- \\
212 \times 10^{-2}\end{array}$ \\
\hline
\end{tabular}

Table 1. Summary of absolute gamma-ray to Cerenkov-light conversion efficiencies.

\footnotetext{
- Per centimeter of uptical fiber.
}

Table 2. Relative Cerenkov-light production for difterent Compton-converter inaterials.

\begin{tabular}{lc}
\hline \multicolumn{1}{c}{$\begin{array}{c}\text { Converter } \\
\text { material }\end{array}$} & $\begin{array}{c}\text { Relative } \\
\text { fiber output }\end{array}$ \\
\hline $1.6 \mathrm{~mm}$ beryilium & 1.00 \\
$3.2 \mathrm{~mm}$ & 0.99 \\
polyethylene $\left(\mathrm{CH}_{2}\right)$ & 0.98 \\
$12.7 \mathrm{~mm}$ LiH & \\
$1.4 \mathrm{~mm}$ & 0.96 \\
polystyrene $(\mathrm{CH})$ & 0.86 \\
$1.6 \mathrm{~mm}$ aluminum & 0.70 \\
$0.8 \mathrm{~mm}$ copper & 0.67 \\
$1.8 \mathrm{~mm}$ lead & 0.42 \\
PCS fiter only &
\end{tabular}




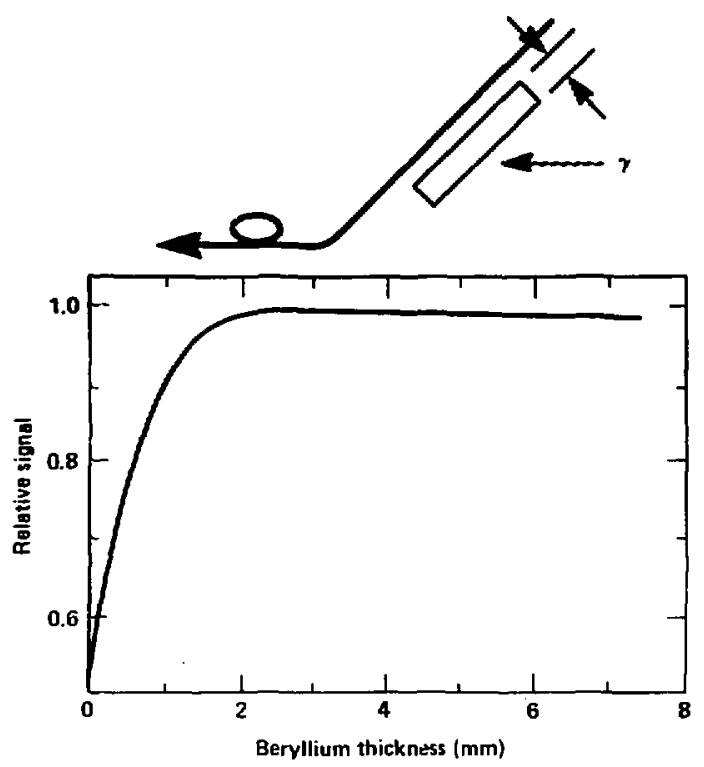

Figure 4. Effect of Compton-converter thickness on Cerenkov light. The angle between the converter/fiber and the gamma heam is $45^{\circ}$

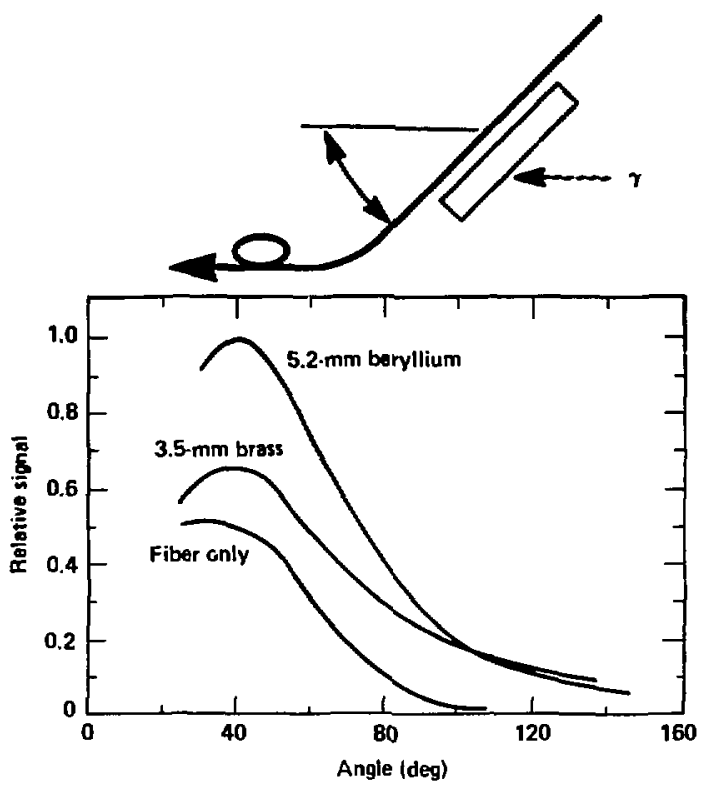

Figure 5. Effect of the angle between the gamma-ray beam and fiher on Cerenkov-light output.

(i'CS) fiber. For the gamma-ray and electron energies involved, a maximum signal was obtained for about a 2-mm thickness. Greater thicknesses caused a slight signal reduction due to gamma-ray absorption.

\section{Effecl of Beam-to-Fiber Angle on Efficiency}

The Cerenkov-light signal strengths were measured for different angles of the fiber/converter with respect to the beam, and confirmed an optimum angle of about $45^{\circ}$. Figure 5 shows the results. Electron scattering, as already briefly discussed, can explain the flatter angular-sensitivity curve for brass compared with that for beryllium.

These data are for a PCS fiber having an unusually small measured numerical aperture, probably the result of poor termination procedures. The data were reproduced almost identically using the Raychem VSC-200A fiber with a numerical aperture of about 0.28 .

\section{Effect of Compton-Converter-to-Fiber Separation Distance}

Most experiments were conducted with the fiber attached to the back side of the Compton-converter plate and centered in the gamma-ray beam. This experiment briefly investigated the effect of separating the fiber from the converter for both a low- $Z$ material (bervllium) and a medium- $Z$ material (brass). Figure 6 gives the results. For both measurements, the collimator diameter was $3.8 \mathrm{~cm}$ and the fiber and converter were at $45^{\circ}$. The results of this experiment would be expected to vary for different beam diameters.

\section{Relative Efficiency of Cerenkov-Light Production with ${ }^{24} \mathrm{Na}$ and ${ }^{60} \mathrm{Co}$}

The ${ }^{\text {th }} \mathrm{Co}$ measurements provide optical-fiber sensitivities for the conversion of gamma rays to Cerenkov light at about $1 \mathrm{MeV}$ only. Tu wbtain sensitivities at a higher photon energy, we performed experiments using a ${ }^{24} \mathrm{Na}$ source. ${ }^{24} \mathrm{Na}$ decays with the emission of two gamma photons, one with an energy of $2.76 \mathrm{MeV}$ and one with an energy of $1.38 \mathrm{MeV}$. To isolste the effect of the 2.76-MeV' photon. ${ }^{01} \mathrm{Co}$ data are used, with appropsiate interpolation, to subtract out the 1.36-MeV photon contribution.

The 2.76-MeV measurements were obtained with small, relatively-low-activity sources in a geometry which is less constrictive than the one used for the "Co measurements described above. The spectrum correction described earlier was not investigated or applited. hut would be experted to be lecis critical.

The relative Cerenkov sensitivity $S_{K}$ of an optical fiber for ${ }^{*} \mathrm{Co}$ (average photon energy $1.25 \mathrm{MeV}$ ) and the 276-MeV photon energy is approximately given by: 


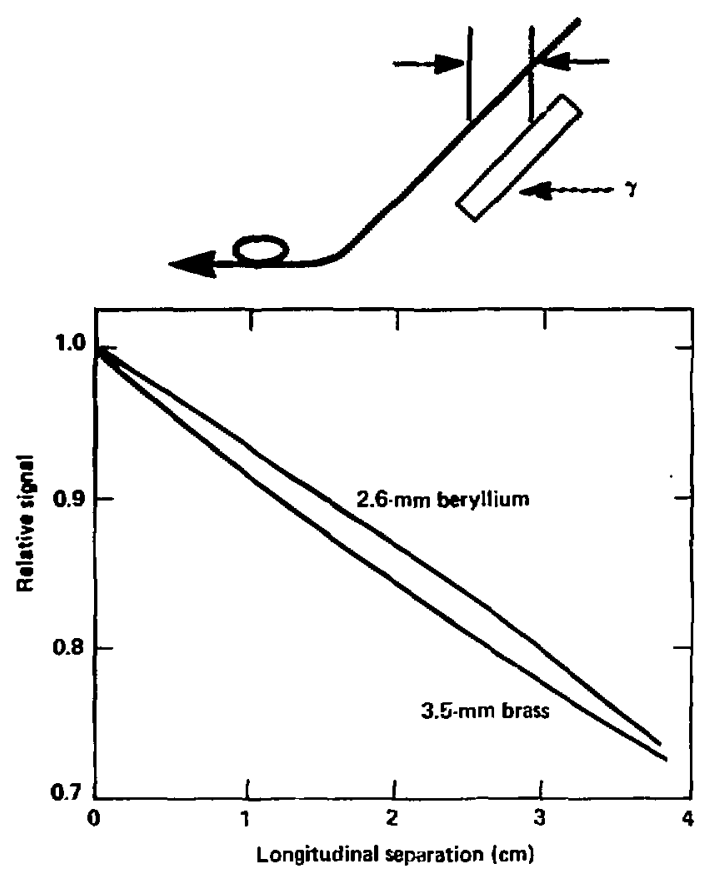

Figure 6. Effect of the distance between the fiber and converter on Cerenkov-light output.

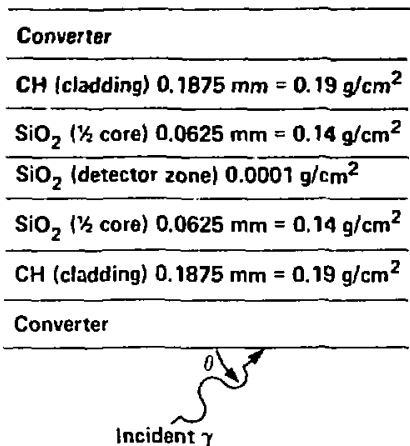

Figure 7 . Geometry simulating a Compton converter and fiber, used in computer calculations of the conversion efficiency of gamma ray's to Cerenkuv light.

$$
S_{\mathrm{R}}=\frac{3 P_{\mathrm{Na}} \phi_{\mathrm{Co}}}{2 P_{\mathrm{Co}} \phi_{\mathrm{Na}}}-\frac{m}{2},
$$

where $P$ is the power of the Cerenkov-light output of the fiber, $\phi$ is the source strength for the appropriate sources, and $m$ is the relat ive fiber sensitivity at $1.38 \mathrm{MeV}$ compared with $1.25 \mathrm{MeV}$. For $\phi$ values given in terms of $\mathrm{MeV} / \mathrm{cm}^{2} \cdot \mathrm{s}$ and for $m=1.02$, the $S_{K}$ value is determined to be about 1.2. A more precise formula is given in Ref. 4 .

\section{Computer Calculations of Gamma-Ray to Cerenkov-Light Conversion Efficiency}

We calculated optical-fiber sensitivities using SANDYL, a Monte Carlo electron-transport code. SANDYL is a generalized threedimensional transport code developed by Sandia National Laboratory, Livermore, based on theoretical and computational methods of Berger and Seltzer at the National Bureau of Standards. "The code is used to calculate the electron flux as a function of energy and angle at the center of optical fibers. Assuming these fluxes to be uniform over the entire fiber core, Cerenkov-light production is calculated by analytic methods.

Figure 7 shows the slab geometry, which simulates a PCS fiber with a $125-\mu \mathrm{m}$ core diameter, and allows for gamma-ray-toelectron converters on both front and back surfaces. Camma rays are incident at an angle $B$ to the front surface, and electron fluxes through the zone at the fiber center are tabulated. Electron fluxes were tallied in 11 energy gr.Jups between the threshold of $0.175 \mathrm{MeV}^{\circ}$ and $10 \mathrm{McV}$. Figures $8 \mathrm{a}$ and $8 \mathrm{~b}$ show, respectively, the fluxes and light-output contributions from the electron-energy groups, as determined by an example calculation for $1.2-\mathrm{MeV}$ gamma rays at $45^{\circ}$ and a 5 -mm-thick beryllium front slub converter.

Equation (9) is the analytic formula for the fraction $F$ of the Cerenkov cone with angle a intercepted by a fiber with numerical s:-ture 0.21 (critical angle for total internal reflectance of $8^{\circ}$ ), and angle $\theta$ between the electron velocity and fiber. 

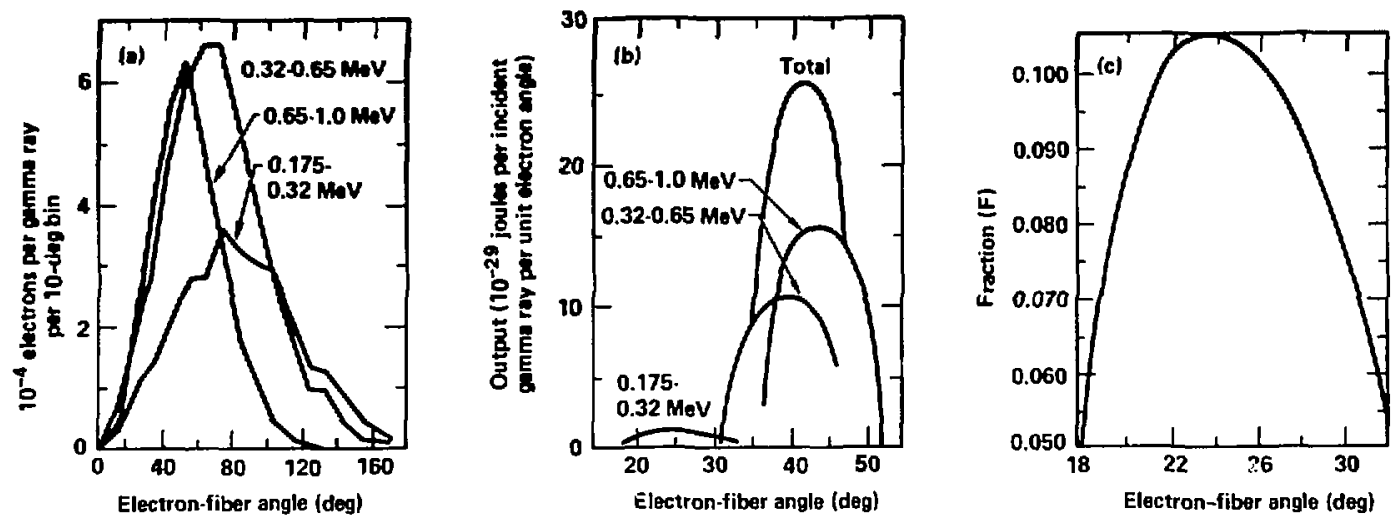

Figure 8. Computer calculations of optical-fiber sensitivities, with the geometry shown in Fig. 7. (a) Electron flux. Each curve represents a different electron-energy range. (b) Cerenkov-light output at three electron-energy ranges. (c) Fraction $F$ of the Cerenkov cone intercepted by a fiber with an $8^{\circ}$ acceptance half-angle (numerical aperture is 0.21 ), at a $25.3^{\circ}$ Cerenkov angle.

$$
\Gamma=\frac{1}{\pi} \arccos \left[\begin{array}{c}
-\cos \theta \\
\tan a \sin \theta
\end{array}+\frac{\sqrt{\cos 2 \theta}+\left(\frac{\left.\sin ^{2} \theta-\cos ^{2} \theta \tan ^{2} 8^{\circ}+1\right)}{\tan \theta}\right)}{\sin \theta-\cdots-\tan ^{2} \alpha}-\right.
$$

For a $25.3^{\circ}$ Cerenkov angle, this formula gives the results shown in Fig. 8c.

We applied this method to calculate the light injected into a 50- $\mu \mathrm{m}$ transmission fiber with a numerical aperture of 0.21 by a PCS detector fiber large enough to fill all available transmission modes. For a typical fission gamma-ray spectrum incident at $45^{\circ}$ on a 5 $\mathrm{mm}$ beryllium converter, the calculated result for light with an $800-\mathrm{nm}$ wavelength is $1.95 \times 10^{-28} \mathrm{~J} / \mathrm{MeV} \cdot \mathrm{cm}^{2} \cdot \mathrm{nm}$ per centimeter of fiber exposed. If this value is adjusted to correspond to a numerical aperture of 0.39 and a fiber core diameter of $125 \mu \mathrm{m}$,

$S_{\text {calc }}=4.2 \times 10^{-27} \mathrm{~J} / \mathrm{MeV} \cdot \mathrm{cm}^{2} \cdot \mathrm{nm}$ per centimeter of fiber. This compares with the values measured at the $800-\mathrm{nm}$ wavelength.

\section{Conclusions}

We have determined the absolute gamma-ray to Cerenkov-light conversion efficiencies for pure-silica-core Raychem VSC-200A and IT\&T PSO-5 fibers, using a ${ }^{60} \mathrm{Co}$ radiation source and a geometry similar to that used in field applications. The relative efficiencies are also described, for changes in Compton-converter material, thickness, angle, and distance from the fiber. We found that efficiencies depend on the gamma-ray energy and on the particular fiber sample and the quality of its terminations. Computer calculations used to determine an efficiency for the PCS fiber produced a result similar to the measurements. This indicates that the physital processes occurring in the conversion of gamma-ray cnergy to Cerenkov-light energy for an optical fiber are reasonably well understoud.

\section{Acknowledgments}

We wish to recognize the assistance provided to this effort by P. Calavan, W. Davis, C. Dittmore, D. Jander, E. Jerbic, F. Roeske, and J. Ticehurst, all at LLNL; P. B. Lyons at LANL; and S. Egdorf at EG\&G, Inc., Las Vegas, Nevada. We also thank the personriel at the LANL reactor facility, where the ${ }^{27} \mathrm{Na}$ source was produced. J. C. Cherniak of iNL's Technical Information Department provided editorial help in preparing this paper. Work performed under the auspices of the U. S. Department of Energy by Lawrence Livermore National Laboratory under Contract No. W-7405-Eng-48, and Los Alamos National Laboratory under Contract No. WT-7405-Eng-36.

\section{References}

1. Rowske, F., Smith. D. E., Pruett, B. L.. and Reedy. R. P.. “A High-Bandwidth Mtultichannel Fiber Optic System for Measuring Gumma Rays" This Procicitings:

2. Clark, D.. "The Intrinsic Scintillation Euficiency of Plastic Scintillalors for "Co Gamma Excitaticn," Niuc. Imstrum. Artheds 117. $295-303(19 \bar{\lambda}+1)$.

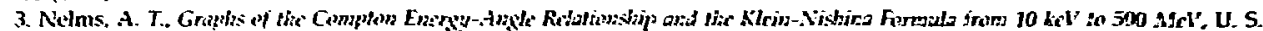
Department of Commerce, National Bureau of Standands, Washington. D.C. NBS Gircular 592 (1953).

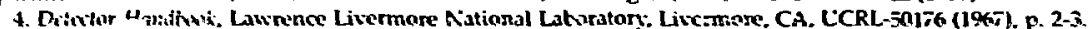

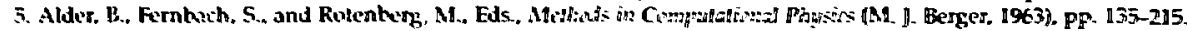

